\title{
Comparative analysis of postoperative pain after transvaginal hybrid NOTES versus traditional laparoscopic cholecystectomy in obese patients
}

\author{
Dirk R. Bulian ${ }^{1}$ (1) - Sebastian Walper ${ }^{1} \cdot$ Dana C. Richards ${ }^{1} \cdot$ Sissy-A. Schulz $^{1} \cdot$ Claudia S. Seefeldt $^{1}$. \\ Panagiotis Thomaidis ${ }^{1}$. Jurgen Meyer-Zillekens ${ }^{1} \cdot$ Markus M. Heiss $^{1}$
}

Received: 13 May 2021 / Accepted: 21 October 2021 / Published online: 3 November 2021

(c) The Author(s) 2021

\begin{abstract}
Purpose Even though obesity is a known risk factor for needing cholecystectomy, most research excludes patients with higher degrees of obesity. The aim of this retrospective study was to compare postoperative pain and analgesic consumption in obese patients, who underwent either transvaginal hybrid Natural Orifice Transluminal Endoscopic Surgery (NOTES) cholecystectomy (NC) or traditional laparoscopic cholecystectomy (LC).

Methods Between 12/2008 and 01/2017, $237 \mathrm{NC}$ were performed, of which 35 (14.8\%) showed a body mass index (BMI) of $35 \mathrm{~kg} / \mathrm{m}^{2}$ or more (obesity II and III according to the World Health Organization). Of these, procedural time, postoperative pain, analgesic requirements, and other early postoperative parameters were collected and compared with 35 matched LC patients from the same time period.

Results There were no differences in the baseline characteristics between the two groups, but we found significant benefits for the hybrid NOTES technique in terms of less pain $(P=0.006)$, coherent with significantly less intake of peripheral (paracetamol; $P=0.005$ ), and of centrally acting analgesics (piritramide; $P=0.047$ ) within the first two-day post-surgery. We also found that those in the NC group had shorter hospital stays $(P<0.001)$. The postoperative complication rates and the procedural time did not differ between the two groups.

Conclusion With regard to postoperative pain and analgesic requirements and without an increase in postoperative complications, obese patients experience short-term benefits from the hybrid NOTES technique compared to traditional laparoscopic cholecystectomy.
\end{abstract}

Keywords Transvaginal NOTES $\cdot$ Cholecystectomy $\cdot$ Pain $\cdot$ Outcome $\cdot$ Obesity $\cdot$ Body mass index

Transvaginal hybrid NOTES cholecystectomy with rigid instruments (NC), first performed by Zornig et al. in June 2007, has become established in some hospitals as an alternative to traditional laparoscopic cholecystectomy (LC) [1]. A meta-analysis of 13 studies demonstrated that, compared to $\mathrm{LC}, \mathrm{NC}$ reduced postoperative pain and postoperative analgesic requirements, while accelerating postoperative convalescence and improving the esthetic surgical outcome without increasing intraoperative or postoperative

Dirk R. Bulian

dirk.bulian@uni-wh.de

1 Department of Abdominal, Tumor, Transplant and Vascular Surgery, Cologne-Merheim Medical Center, Witten/

Herdecke University, Ostmerheimer Strasse 200,

51109 Cologne, Germany complication rates [2,3]. However, most studies excluded patients with higher degrees of obesity [4], which is a risk factor for cholecystolithiasis and hence the need for cholecystectomy [5]. In a 2018 comparative analysis, we demonstrated the feasibility of $\mathrm{NC}$ in patients with a particularly high body mass index (BMI), showing that although these patients required a longer operative time and had a significantly higher probability of additional trocar use, they experienced similar postoperative lengths of stay and complication rates when compared to patients with normal weight [4]. Thus, our question now was whether the advantages of NC also apply to higher-risk obese patients. Therefore, we compared short-term outcomes for obese patients with a BMI of $35 \mathrm{~kg} / \mathrm{m}^{2}$ or more, on whom we operated using the NC technique, with obese patients who had an LC operation. 


\section{Materials and methods}

\section{Patients}

Between December 2008 and January 2017, 946 cholecystectomies were performed at Cologne-Merheim Medical Center. Of these, 588 procedures were performed on female patients; 237 were performed using the hybrid NOTES technique and 351 using LC. Thirty-five of the $237 \mathrm{NC}$ patients had a BMI of $35 \mathrm{~kg} / \mathrm{m}^{2}$ or more, corresponding to obesity $\mathrm{II}^{\circ}$ or $\mathrm{III}^{\circ}$ according to the WHO classification. As a control group, the first 35 patients who matched the NC group in terms of BMI $(\geq 35 \mathrm{~kg} /$ $\mathrm{m}^{2}$ ), age, and surgical urgency were selected from the 351 LC patients (Fig. 1). Furthermore, we assessed the ASA (American Society of Anesthesiologists) classification and history of major abdominal surgery. Notably, emergency surgery was excluded to obtain as homogeneous a comparison group as possible. Also, procedures differing from the standard technique (4-trocar technique with 6 $\mathrm{mm}$ as well as 11-mm trocars) were excluded when creating the traditionally laparoscopic control group.

\section{Inclusion and exclusion criteria for transvaginal approach}

In principle, our clinic offers the hybrid NOTES technique to all female patients as an alternative to traditional laparoscopic surgery. Contraindications for the transvaginal procedure were as follows: nonadjustable cervix in patients who were not hysterectomized; ongoing pregnancy; genital infections; known endometriosis; and neoplasms of the vulva, vagina, or cervix. These criteria did not result in the exclusion of any patients from the TVC procedure.

\section{Surgical technique}

Transvaginal/transumbilical hybrid NOTES cholecystectomy was performed with rigid reusable instruments in the lithotomy position. The surgeon stood on the left side of the patient with the assistant between the legs. The capnoperitoneum up to $11-15 \mathrm{mmHg}$ was created via Veres needle, which was inserted at the umbilicus after a small incision in the depth of the navel. A 6-mm trocar (Karl Storz GmbH \& Co KG, Tuttlingen, Germany) was inserted transumbilically after safety tests and removal of the Veres needle. A diagnostic laparoscopy was performed by a transumbilical 5-mm optic $\left(45^{\circ}, 29 \mathrm{~cm}\right.$ long, Karl Storz GmbH \& Co KG,

Fig. 1 Trial flow diagram

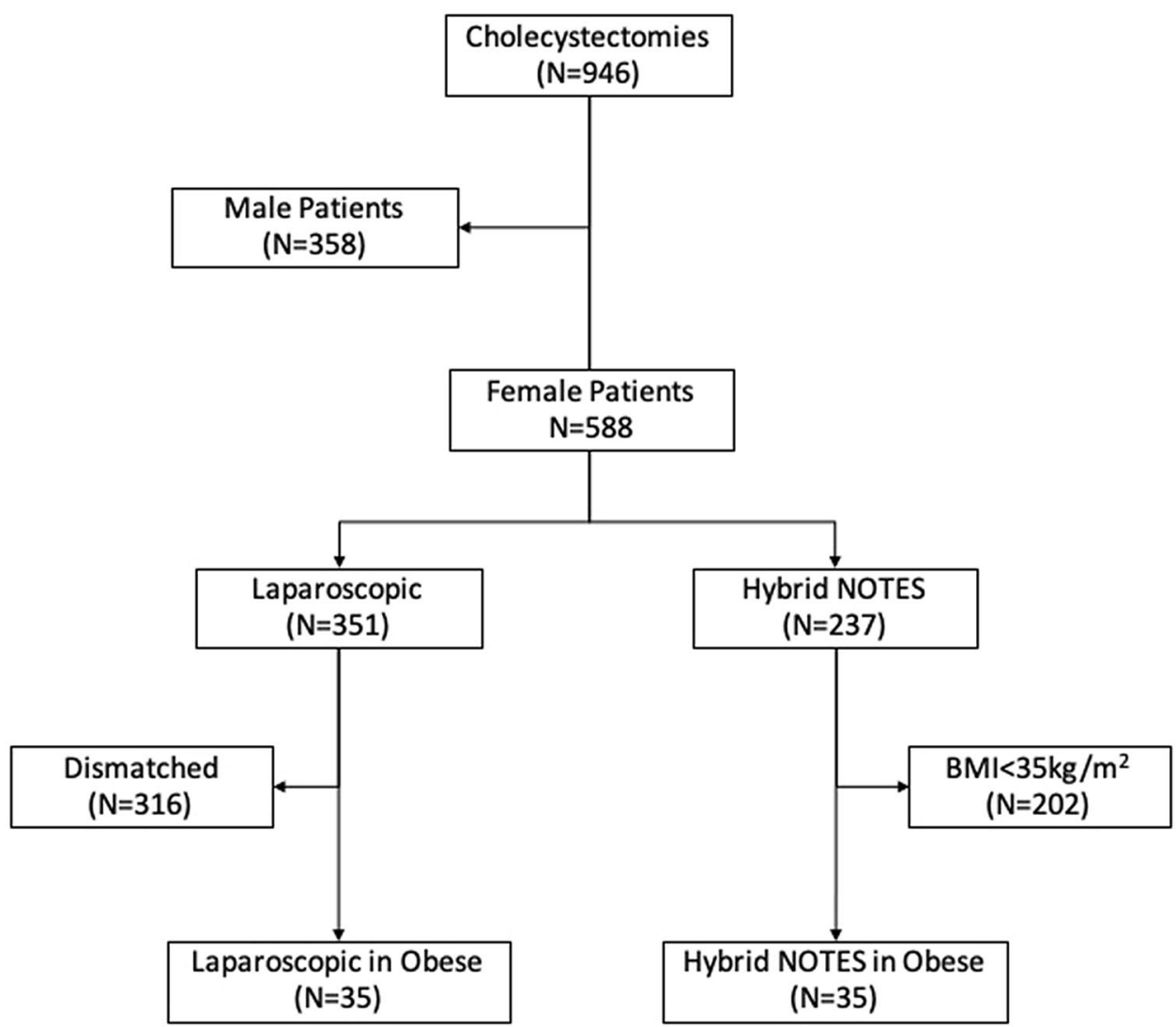


Tuttlingen, Germany) and the Douglas was exposed in a Trendelenburg position. A curved 5-mm grasping forceps (according to CUSCHIERI O-CON, $43 \mathrm{~cm}$ long, Karl Storz GmbH \& Co KG, Tuttlingen, Germany) and a transvaginal 11-mm trocar without connector for insufflation (Karl Storz GmbH \& Co KG, Tuttlingen, Germany) were inserted via the posterior vault of the vagina under sight via the umbilical trocar. The gallbladder was hold with the curved grasper and the camera was changed to a 10 -mm optic (45 degrees, $42 \mathrm{~cm}$ long, Karl Storz GmbH \& Co KG, Tuttlingen, Germany), which was inserted via the transvaginal 11-mm trocar. The dissection of the gallbladder, the cystic duct, and the cystic artery, as well as clipping (Endo Clip 5-mm clip applier, Covidien, MA, USA) and transecting of them was performed via the umbilical 6-mm trocar in the standard fashion. The gallbladder was then transvaginally removed through the 11-mm trocar incision in the posterior vault using a retrieval bag (Endo Catch Gold, Covidien, MA, USA) after changing the view to the transumbilical 5-mm optic. The 2 small incisions in the posterior vault were closed with resorbable sutures. In difficult cases, an additional 6-mm trocar (Karl Storz GmbH \& Co KG, Tuttlingen, Germany) was used at the right costal margin. The described technique was not changed throughout the period.

Traditional laparoscopic cholecystectomy was performed in the supine position with legs apart. The surgeon stood on either the left side of the patient with the assistant between the legs or vice versa. Four trocars $(6 \mathrm{~mm}$ and $11 \mathrm{~mm}$; Karl Storz GmbH \& Co KG, Tuttlingen, Germany) were used and the capnoperitoneum up to 11-15 $\mathrm{mmHg}$ was created either via Veres needle or via the first 11-mm trocar, which was inserted at the umbilicus in an open technique. Dissection of the gallbladder did not differ between the two techniques and was performed regularly with the stromal hook. The cystic duct and cystic artery were closed centrally and peripherally with clips in each case after reaching the "view of safety." In all cases, the gallbladder was removed transumbilically in a retrieval bag (ExBag, Medi-Globe $\mathrm{GmbH}$, Achenmuehle, Germany). The umbilical fascia and skin incision were widened according to the size of the gallstones and closed with sutures in each case.

Although the German guideline does not suggest the use of perioperative antibiotic prophylaxis in the context of elective laparoscopic cholecystectomy in low-risk patients, patients with obesity, among others, are considered highrisk patients, so that according to our intern guidelines all patients in this study received a preoperative, intravenous antibiotic single-shot prophylaxis with Ampicillin $2 \mathrm{~g}$ and Sulbactam $1 \mathrm{~g}$ [6].

At our hospital, there is no difference in the postoperative treatment after the techniques described. Full mobilization as well as oral feeding, in absence of nausea or vomiting, is intended on the day of surgery. The postoperative analgesic standard consists of $1000 \mathrm{mg}$ paracetamol administered intravenously every $6 \mathrm{~h}$ on the day of surgery, $1000 \mathrm{mg}$ paracetamol administered three times per os on the first postoperative day, and $500 \mathrm{mg}$ paracetamol administered three times per os on the second postoperative day. In addition, the intravenous administration of $3.75 \mathrm{mg}$ to $15 \mathrm{mg}$ of piritramide (an opioid with a morphine-equivalence factor of 0.7) was provided if needed. Any standard pain medication not taken by the patients was documented by the nursing staff. If an allergy was known or occurred in the course, medication was adjusted accordingly. Thromboembolism prophylaxis consisted of a low-molecular weight heparin. Patients were discharged on the second postoperative day if clinical condition, wound healing, and blood test results allowed it. A discharge prior to the second postoperative day is financially penalized by the German health insurance billing system and thus not sought.

\section{Outcome parameter}

In all patients, age, sex, height, weight, surgical technique, reason for cholecystectomy (symptomatic cholecystolithiasis; cholecystitis; choledocholithiasis; biliary pancreatitis), procedural time, analgesic administration (peripheral acting analgesics and centrally acting analgesics; regular and additional requirement), pain intensity, postoperative complications, and postoperative length of stay were documented. For $\mathrm{NC}$, some of the parameters were prospectively entered into a dedicated registry and the remaining data were collected retrospectively from clinical documentation.

To be able to detect a difference in existing preoperative pain as well as to account for preoperative analgesic intake due to different underlying diseases, these were also documented and analyzed.

For postoperative pain assessment, the numeric rating scale (NRS) is used by trained nurses twice per day and additionally six hours after surgery, documenting the pain level between 0 (no pain) and 10 (worst imaginable pain).

Postoperative complications were classified and compared according to Clavien/Dindo [7].

\section{Statistics}

The data were prepared in Microsoft Excel, and SPSS Statistics 27 (IBM Corp., Armonk, NY, USA) was used for the statistical analyses and data processing of all variables. Data of continuous variables are expressed as median and interquartile range. Binary and categorical variables are reported as counts and percentages. The Mann-Whitney U test was used for continuous parameters, the Chi-square test for categorical parameters, and the Chi-square test for trend for ordinally scaled variables. A $P$-value less than 0.05 was considered statistically significant. 


\section{Results}

The patient parameters such as age, height, weight, BMI, indication for cholecystectomy, ASA classification, history of major abdominal surgery, preoperative pain, and need for preoperative analgesics were all comparable and did not differ significantly between groups (Table 1).

The postoperative pain on the morning of the first postoperative day $(P=0.001)$ and on the morning of the second postoperative day $(P=0.002)$ as well as the sum of pain measurements from the day of surgery to the morning of the second postoperative day $(P=0.006)$ was significantly lower in the NC group compared to the LC group (Fig. 2 and Fig. 3).

The intake of peripheral analgesics (paracetamol) was significantly lower in the NC group compared to the LC group on the day of surgery $(P<0.001)$ and on the second postoperative day $(P<0.001)$, whereas the differences in the recovery room and on the first postoperative day are not significant (Fig. 4). Figure 5 shows a significant reduction of the daily intake of centrally acting analgesics (piritramide) by the hybrid NOTES technique only at the second postoperative day $(P=0.011)$. Table 2 reflects the cumulative amounts of peripheral and centrally acting analgesics from surgery to the second postoperative day, which were both significantly lower in the NC group $(P=0.005$ and $P=0.047)$.

There were no significant differences between the groups in procedural time, demand of medication, postoperative complications and their classifications due to Clavien/Dindo, and mortality (Tab. 2). In contrast, the postoperative length of stay, also listed in Table 2, was significantly shorter in the NC group than in the LC group $(P<0.001)$.

In 21 patients, no additional transcutaneous auxiliary trocar had to be used. In 11 patients one additional trocar was necessary, in one patient two and in two cases even three auxiliary trocars were required.
Table 1 Baseline characteristics of all patients

\begin{tabular}{|c|c|c|c|c|}
\hline Variable & $\mathrm{NC}(n=35)$ & $\mathrm{LC}(n=35)$ & Total $(n=70)$ & $P$ value \\
\hline Age [years] & $43.0(25-63)$ & $45.0(25-72)$ & $43.5(25-72)$ & 0.182 \\
\hline Height $[\mathrm{cm}]$ & $165(150-184)$ & $167(155-179)$ & $166.5(150-184)$ & 0.874 \\
\hline Weight $[\mathrm{kg}]$ & $112(80-171)$ & $111(85-150)$ & $112(80-171)$ & 0.613 \\
\hline BMI $\left[\mathrm{kg} / \mathrm{m}^{2}\right]$ & $40.6(35.3-57.8)$ & $41.2(35.4-54.7)$ & 40.8 (35.3-57.8) & 0.553 \\
\hline Indication & & & & 0.459 \\
\hline Symptomatic cholecystolithiasis & $33(94.3)$ & $29(82.9)$ & $62(88.6)$ & \\
\hline Cholecystitis & $1(2.9)$ & $3(8.6)$ & $4(5.7)$ & \\
\hline Choledocholithiasis & $1(2.9)$ & $2(5.7)$ & $3(4.3)$ & \\
\hline Biliary pancreatitis & $0(0)$ & $1(2.9)$ & $1(1.4)$ & \\
\hline ASA & & & & 0.611 \\
\hline 1 & $0(0)$ & $0(0)$ & $0(0)$ & \\
\hline 2 & $13(28.6)$ & $10(37.1)$ & $23(32.9)$ & \\
\hline 3 & $22(71.4)$ & $25(62.9)$ & $47(67.1)$ & \\
\hline History of major abdominal surgery & & & & 1.000 \\
\hline Yes & $5(14.3)$ & $6(17.1)$ & $11(15.7)$ & \\
\hline No & $30(85.7)$ & $29(82.9)$ & $59(84.3)$ & \\
\hline Preoperative pain [NRS] & & & & 0.741 \\
\hline 0 & $31(88.6)$ & $31(88.6)$ & $62(88.6)$ & \\
\hline 1 & $1(2.9)$ & $0(0)$ & $1(1.4)$ & \\
\hline 2 & $1(2.9)$ & $2(5.7)$ & $3(4.3)$ & \\
\hline 3 & $1(2.9)$ & $2(5.7)$ & $3(4.3)$ & \\
\hline 7 & $1(2.9)$ & $0(0)$ & $1(1.4)$ & \\
\hline Need of preoperative analgesics & & & & 1.000 \\
\hline Yes & $4(11.4)$ & $4(11.4)$ & $8(11.4)$ & \\
\hline No & $31(88.6)$ & $31(88.6)$ & $62(88.6)$ & \\
\hline
\end{tabular}

Values are reported as median (min-max) and counts (percentage)

$N C$ transvaginal hybrid NOTES cholecystectomy, $L C$ traditional 4-trocar laparoscopic cholecystectomy, $B M I$ Body Mass Index, NRS Numeric Rating Scale, ASA American Society for Anesthesiologists 


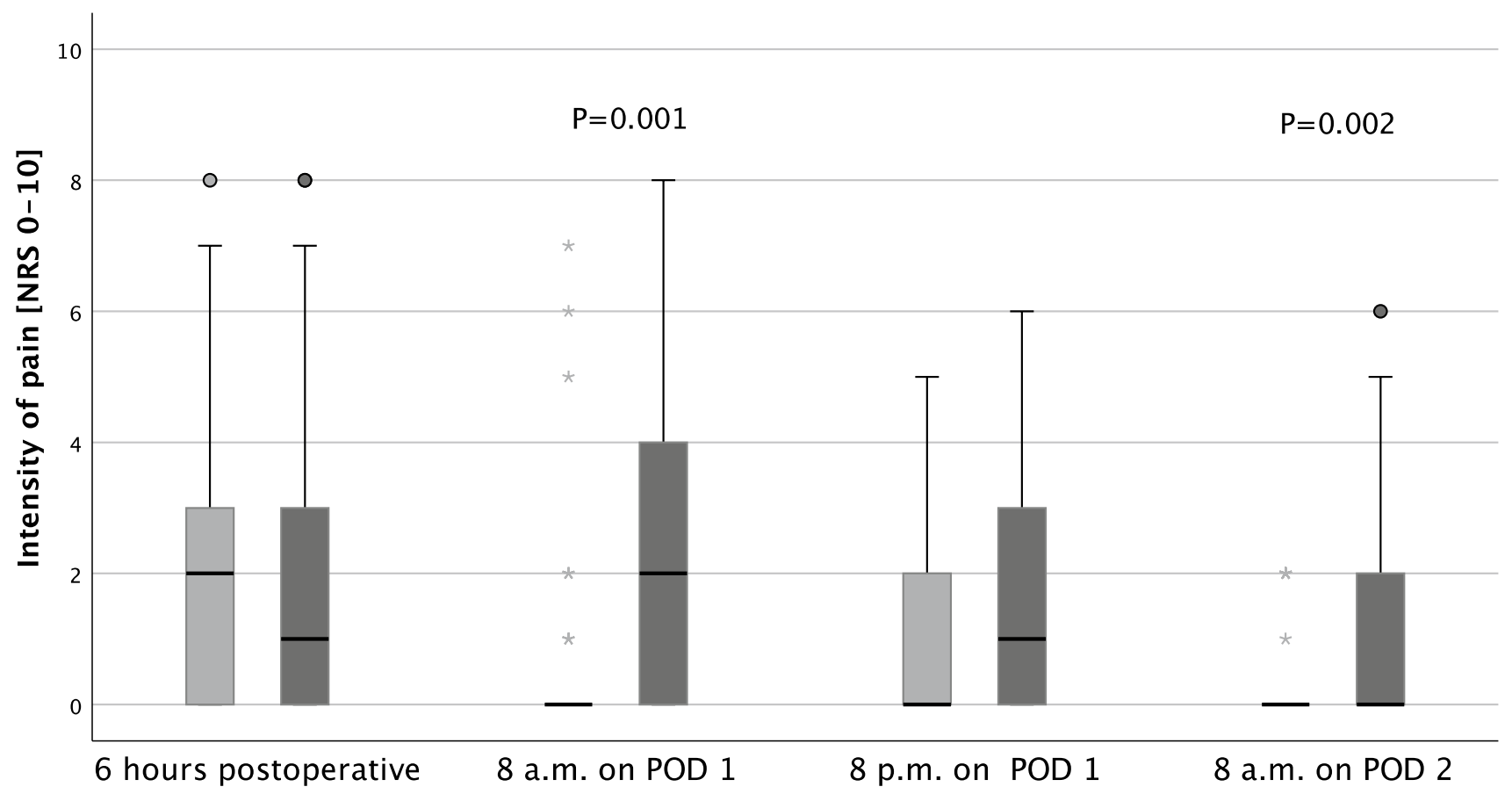

NRS: Numeric Rating Scale

Hybrid NOTES cholecystectomy POD: Postoperative day

Fig. 2 Daily intensity of pain

\section{Discussion}

Using a retrospective group comparison of 35 very obese patients (BMI $\geq 35 \mathrm{~kg} / \mathrm{m}^{2}$ ) in each group who had undergone traditional laparoscopic cholecystectomy or transvaginal/ transumbilical hybrid NOTES cholecystectomy, we found significant advantages for the hybrid NOTES group in terms of less pain despite lower use of peripheral and centrally acting analgesics, as well as a significantly shorter postoperative length of stay. Although the difference in cumulative piritramide dose showed only marginal significance, this may possibly be due to the high-dose variation.

Minimal invasive surgery (MIS) is designed to reduce access trauma during resection and reconstructive intraabdominal procedures by replacing laparotomy with minimized trocar access with the goal of shortening postoperative hospital stay and reconvalescence by reducing pain, among other benefits. NOTES is the logical evolution of MIS, in which trocar access and retrieval incision through the abdominal wall are also eliminated and access to the abdominal cavity is achieved by penetrating an intra-abdominal hollow organ through natural body orifices, such as the stomach (transoral) or the posterior vaginal vault (transvaginal) $[8,9]$. A great benefit of this approach is the lack of pain reception due to nonexistent pain fibers in the area of the posterior vaginal vault, for example, [10] and thus a complete reduction of pain resulting from the access path. However, this only partly accounts for intraoperative and postoperative pains; postoperative analgesia is often still necessary. The intra-abdominal surgery itself is not different from the laparoscopic technique. Thus, it only uses a different access pathway and is not a completely different procedure. Because pure NOTES procedures make triangulation difficult or would require the use of flexible instruments with inadequate intraperitoneal navigation, NOTES is usually supplemented in the routine clinical practice by one or more transcutaneous auxiliary trocars, which has led to the term "hybrid NOTES." The hybrid technique is the leading technique in most hospitals performing NOTES procedures [11].

Several meta-analyses have shown various advantages of transvaginal NOTES over traditional laparoscopy, such as less postoperative pain, less postoperative analgesic medication, a shorter length of stay, and a shorter time of recovery with no statistically different intra- and postoperative complication rates $[2,12,13]$. However, obese patients were mostly excluded in the underlying studies, as we already elaborated on in 2018 [4]. Obesity is a risk factor for the development of cholecystolithiasis and the need for surgical therapy [5, 14]. Furthermore, significant weight loss, which is more commonly sought in obese patients, whether achieved by diet or surgery, is also an independent risk factor 


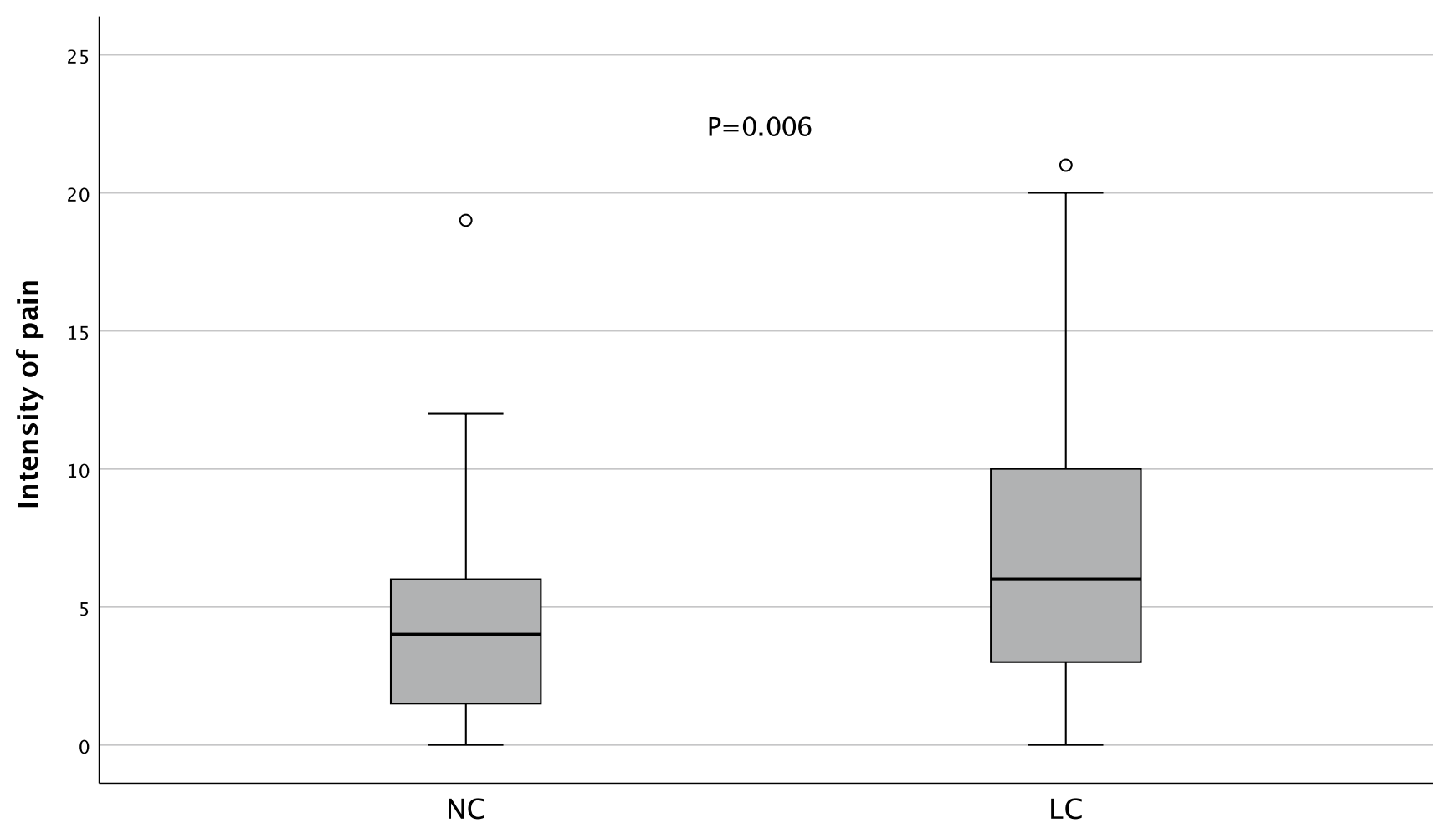

NC: Hybrid NOTES cholecystectomy

LC: Laparoscopic cholecystectomy

Fig. 3 Cumulative pain

for the development of gallstone disease $[15,16]$. Thus, the question arises whether $\mathrm{NC}$, which is beneficial for normal or overweight to mildly obese individuals, is also feasible and beneficial for the high-risk group of the very obese. After demonstrating in 2018 that NC is also feasible in very obese patients without increasing intraoperative or postoperative complication rates compared with $\mathrm{NC}$ in normal weight patients, as well as resulting in comparable postoperative lengths of stay [4], we sought to clarify whether the advantages comparing the two surgical techniques are also demonstrable in patients with a BMI of at least $35 \mathrm{~kg} / \mathrm{m}^{2}$.
Therefore, we performed a retrospective analysis of patients from the aforementioned study in terms of outcome parameters compared with LC patients of the same time period.

In obese women, the esthetic results are sometimes disputable, which is why we did not analyze this point.

A limit of our analysis is the retrospective study design, although we tried to minimize presumptive bias by selecting patients according to comparable patient-side parameters such as age and surgical urgency from the same time period. Despite some matching the percentage of uncomplicated cases (e.g., no history of inflammation) was lower in the 


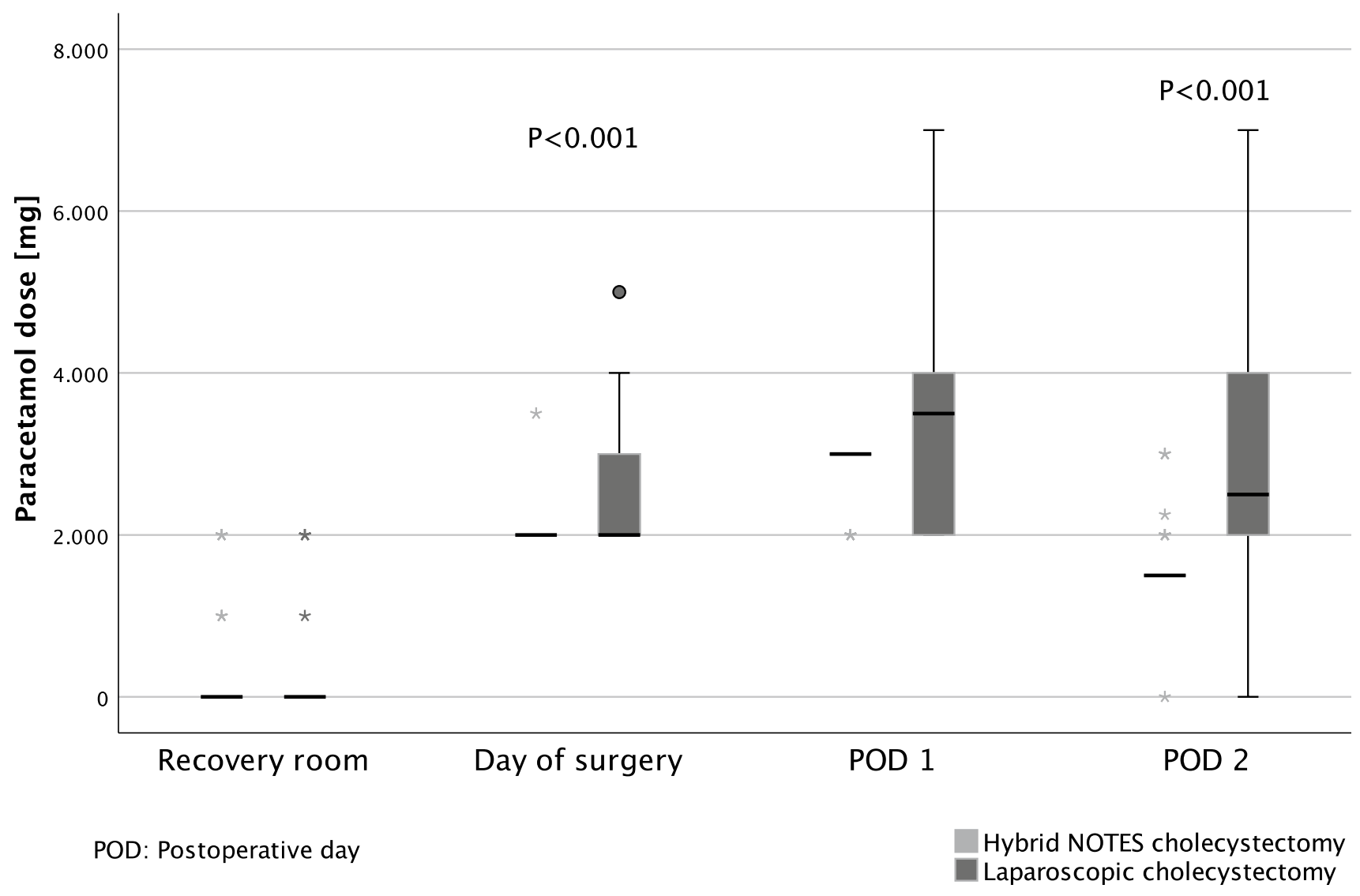

Fig. 4 Daily use of paracetamol

traditional laparoscopic group compared to the hybrid which may represent some bias, although the difference was not significant. Nevertheless, this retrospective setting is a high limitation, and a prospective study in a multicenter setting is needed to confirm our findings. Another limitation of the study is the small number of patients.

Furthermore, $\mathrm{NC}$ is performed primarily in centers of excellence in minimally invasive surgery by very skilled surgeons, so the results should be applied with caution to daily practice.

\section{Conclusion}

This is the first analysis comparing postoperative shortterm parameters after NC versus LC in very obese patients (BMI $\geq 35 \mathrm{~kg} / \mathrm{m}^{2}$ ). We found advantages of NC in terms of significantly less pain despite less analgesic use as well as significantly shorter postoperative length of stay for NC patients. Thus, we were able to confirm the advantages shown in normal weight to slightly obese patients for this group of patients, who are particularly at risk of gallstone disease and the need of cholecystectomy.

Acknowledgements The authors thank Emma Banchoff, Ann Arbor, Michigan, USA for proofreading.

Funding Open Access funding enabled and organized by Projekt DEAL.

\section{Declarations}

Disclosures Drs. Dirk R. Bulian, Sebastian Walper, Dana C. Richards, Sissy-A. Schulz, Claudia S. Seefeldt, Panagiotis Thomaidis, Jurgen Meyer-Zillekens, and Markus Maria Heiss have no conflict of interest or financial ties to disclose. 


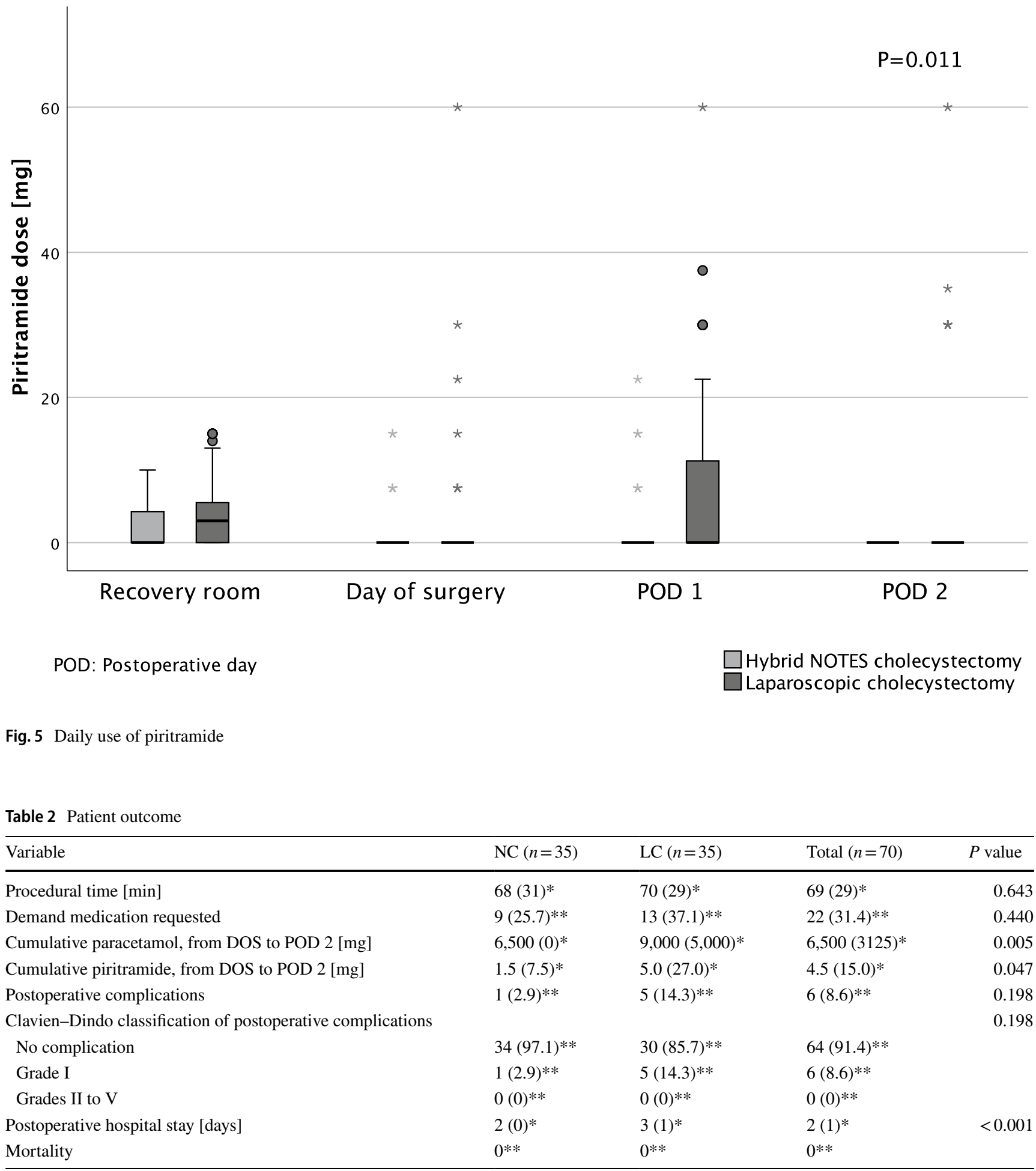

Values are reported as median (interquartile range)* and counts (percentage)**

$N C$ transvaginal hybrid NOTES cholecystectomy, $L C$ traditional 4-trocar laparoscopic cholecystectomy, $D O S$ day of surgery, $P O D$ postoperative day

Ethical approval The study protocol was approved by the Research Ethics Committee of Witten/Herdecke University on April 24, 2018 (No. $44 / 2018$ ) and meets the guidelines of the responsible governmental agency. Written and informed consent regarding the performed procedures as well as potential future analyses of their data were obtained from all patients. 
Open Access This article is licensed under a Creative Commons Attribution 4.0 International License, which permits use, sharing, adaptation, distribution and reproduction in any medium or format, as long as you give appropriate credit to the original author(s) and the source, provide a link to the Creative Commons licence, and indicate if changes were made. The images or other third party material in this article are included in the article's Creative Commons licence, unless indicated otherwise in a credit line to the material. If material is not included in the article's Creative Commons licence and your intended use is not permitted by statutory regulation or exceeds the permitted use, you will need to obtain permission directly from the copyright holder. To view a copy of this licence, visit http://creativecommons.org/licenses/by/4.0/.

\section{References}

1. Zornig C, Emmermann A, von Waldenfels HA, Mofid H (2007) Laparoscopic cholecystectomy without visible scar: combined transvaginal and transumbilical approach. Endoscopy 39(10):913-915

2. Yang E, Nie D, Li Z (2019) Comparison of major clinical outcomes between transvaginal notes and traditional laparoscopic surgery: a systematic review and meta-analysis. J Surg Res 244:278-290. https://doi.org/10.1016/j.jss.2019.06.012

3. van den Boezem PB, Velthuis S, Lourens HJ, Cuesta MA, Sietses C (2014) Single-incision and NOTES cholecystectomy, are there clinical or cosmetic advantages when compared to conventional laparoscopic cholecystectomy? A case-control study comparing single-incision, transvaginal, and conventional laparoscopic technique for cholecystectomy. World J Surg 38(1):25-32. https://doi. org/10.1007/s00268-013-2221-4

4. Bulian DR, Knuth J, Thomaidis P, Rieger A, Seefeldt CS, Lange J, Meyer J, Stroehlein MA, Heiss MM (2018) Does obesity influence the results in Transvaginal Hybrid-NOTES cholecystectomy? Surg Endosc 32(11):4632-4638. https://doi.org/10.1007/ s00464-018-6216-y

5. Talseth A, Ness-Jensen E, Edna TH, Hveem K (2016) Risk factors for requiring cholecystectomy for gallstone disease in a prospective population-based cohort study. Br J Surg 103(10):1350-1357. https://doi.org/10.1002/bjs.10205

6. Gutt C, Jenssen C, Barreiros AP, Gotze TO, Stokes CS, Jansen PL, Neubrand M, Lammert F, fur die Teilnehmer der K, Deutsche Gesellschaft fur Innere Medizin e V, Osterreichische Gesellschaft fur Gastroenterologie und H, Schweizer Gesellschaft fur G, Gesellschaft fur H, Deutsche Gesellschaft fur Ultraschall in der M, Deutsche Gesellschaft fur C, Institut fur Qualitatssicherung und Transparenz im G, Deutsche Arbeitsgemeinschaft zum Studium der L, Deutsche R, Deutsche Leberhilfe e V (2018) [Updated S3-Guideline for Prophylaxis, Diagnosis and Treatment of Gallstones. German Society for Digestive and Metabolic Diseases (DGVS) and German Society for Surgery of the Alimentary
Tract (DGAV) - AWMF Registry 021/008]. Z Gastroenterol 56 (8):912-966. https://doi.org/10.1055/a-0644-2972

7. Dindo D, Demartines N, Clavien PA (2004) Classification of surgical complications: a new proposal with evaluation in a cohort of 6336 patients and results of a survey. Ann Surg 240(2):205-213

8. Kalloo AN, Singh VK, Jagannath SB, Niiyama H, Hill SL, Vaughn CA, Magee CA, Kantsevoy SV (2004) Flexible transgastric peritoneoscopy: a novel approach to diagnostic and therapeutic interventions in the peritoneal cavity. Gastrointest Endosc 60(1):114-117

9. Tsin DA (2001) Culdolaparoscopy: a preliminary report. JSLS : Journal of the Society of Laparoendoscopic Surgeons 5(1):69-71

10. Weyl A, Chantalat E, Daniel G, Bordier B, Chaynes P, Doumerc N, Malavaud B, Vaysse C, Roumiguie M (2021) Transvaginal minimally invasive approach: an update on safety from an anatomical, anatomopathological and clinical point of view. J Gynecol Obstet Hum Reprod 50(1):101941. https://doi.org/10.1016/j. jogoh.2020.101941

11. Lehmann KS, Zornig C, Arlt G, Butters M, Bulian DR, Manger R, Burghardt J, Runkel N, Purschel A, Koninger J, Buhr HJ (2015) [Natural orifice transluminal endoscopic surgery in Germany: Data from the German NOTES registry]. Der Chirurg; Zeitschrift fur alle Gebiete der operativen Medizen 86 (6):577-586. https:// doi.org/10.1007/s00104-014-2808-9

12. Peng C, Ling Y, Ma C, Ma X, Fan W, Niu W, Niu J (2016) Safety outcomes of NOTES cholecystectomy versus laparoscopic cholecystectomy: a systematic review and meta-analysis. Surg Laparosc Endosc Percutaneous Techn 26(5):347-353. https://doi.org/ 10.1097/SLE.0000000000000284

13. Xu B, Xu B, Zheng WY, Ge HY, Wang LW, Song ZS, He B (2015) Transvaginal cholecystectomy vs conventional laparoscopic cholecystectomy for gallbladder disease: a meta-analysis. World J Gastroenterol: WJG 21(17):5393-5406. https://doi.org/10.3748/wjg. v21.i17.5393

14. Shabanzadeh DM, Sorensen LT, Jorgensen T (2016) Determinants for gallstone formation - a new data cohort study and a systematic review with meta-analysis. Scand J Gastroenterol 51(10):12391248. https://doi.org/10.1080/00365521.2016.1182583

15. Yang H, Petersen GM, Roth MP, Schoenfield LJ, Marks JW (1992) Risk factors for gallstone formation during rapid loss of weight. Dig Dis Sci 37(6):912-918. https://doi.org/10.1007/BF01300390

16. Alsaif FA, Alabdullatif FS, Aldegaither MK, Alnaeem KA, Alzamil AF, Alabdulkarim NH, Aldohayan AD (2020) Incidence of symptomatic cholelithiasis after laparoscopic sleeve gastrectomy and its association with rapid weight loss. Saudi J Gastroenterol 26(2):94-98. https://doi.org/10.4103/sjg.SJG_472_19

Publisher's Note Springer Nature remains neutral with regard to jurisdictional claims in published maps and institutional affiliations. 